\title{
Accuracy of Food Preference Predictions in Couples
}

\author{
Benjamin Scheibehenne, Jutta Mata, and David Richter
}

\section{Published in:}

Appetite, Vol. 133. Advance online publication.

https://doi.org/10.1016/j.appet.2018.11.021

\section{Citation:}

Scheibehenne, B., Mata, J. \& Richter, D. (2019, February 1). Accuracy of food preference predictions in couples. Appetite, Vol. 133, 344-352.

https://doi.org/10.1016/j.appet.2018.11.021.

\section{Corresponding author:}

Benjamin Scheibehenne, University of Geneva, Geneva School of Economics and Management, 40 bd du Pont-d'Avre, 1211 Geneva, Switzerland

Phone: +41 22379 9498. E-mail: benjamin.scheibehenne@unige.ch

\section{Author Note}

The authors would like to thank the University of Geneva Research Center for Statistics for their help in analyzing the data and Deborah Anne Bowen for her help in copyediting the manuscript. 


\begin{abstract}
The goal of this study was to identify and empirically test variables that indicate how well partners in relationships know each other's food preferences. Participants $(n=2,854)$ lived in the same household and were part of a large, nationally representative panel study in Germany. Each partner independently predicted the other's preferences for several common food items. Results show that predictive accuracy was higher for likes and for extreme and stereotypical preferences as compared to dislikes and for moderate and idiosyncratic preferences. Accuracy was also higher for couples with a high similarity in preferences and with longer relationship duration but was independent of participants' age after controlling for relationship duration. The data also show that relationship duration was accompanied by higher similarity in couples' food preferences. There was a small positive correlation between partner knowledge and both partner similarity and satisfaction with family life, but no correlation between partner knowledge and general life satisfaction. The results reconcile both valence and base-rate accounts of preference prediction accuracy.
\end{abstract}

Keywords: Socio-Economic Panel (SOEP), prediction accuracy, food preferences, romantic couples, perspective-taking 
Food is a central part of human life and human relationships (Drewnowski \& Hann, 1999). Every day, people are required to make predictions about other people's food preferences, for instance, when deciding what foods to purchase and prepare for family members (e.g. Roos, Lehto, \& Ray, 2012; Russell, Worsley, \& Liem, 2015). Eating together is also an important part of long-term relationships that can be a source of both enjoyment and conflict (Bove, Sobal, \& Rauschenbach, 2003). Sharing meals provides an opportunity to communicate with family members and to observe their food preferences (Hartmann, Dohle, \& Siegrist, 2014). Knowing and accurately predicting which foods one's partner likes and dislikes, and feeling that one's own likes and dislikes are understood have been shown to increase subjective well-being (Decuyper, De Bolle \& De Fruyt, 2012; Finkenauer \& Righetti, 2011; Thomas \& Fletcher, 2003; Thomas, Fletcher, \& Lange, 1997). On a societal level, making better predictions in general can lower economic costs (e.g., Waldfogel, 1993) and can help in reducing food waste in particular, which has become an important issue in sustainability (Aschemann-Witzel, 2015; Parfitt, Barthel, \& Macnaughton, 2010).

Even though predicting food preferences is a common activity in daily life, little is known about the factors that determine the accuracy of food preference prediction in couples. The few studies that address this issue rely on relatively small samples that make it difficult to generalize the results. To bridge this gap, the paper at hand uses a large, nationally representative sample of couples living in Germany to test measures that correlate with predictive accuracy for common foods. As outlined in more detail below, we focus on key concepts and measures that have been identified and discussed in the literature, including valence, strength, and idiosyncrasy of preferences as well as couples' age and relationship duration. The data also make it possible to 
analyze similarities in food preferences between partners and possible correlations of accurate partner knowledge in the food domain and relationship satisfaction as well as satisfaction with family life.

\section{Valence}

Past research indicates that prediction accuracy of personal choice by individuals depends on valence, that is, whether a predicted "target" likes or dislikes an item. For example, Gershoff, Mukherjee, and Mukhopadhyay $(2003,2007)$ suggest that other people's likes are easier to predict than their dislikes because they are often less ambiguous and hence more reliable. In a similar vein, a study on predicting school lunch choices found that parents were better at predicting their children's likes than dislikes (Mata, Scheibehenne \& Todd, 2008).

Other research suggests the opposite, namely that dislikes are easier to predict than likes because negative information is often regarded as more important and diagnostic (Ahluwalia, 2002; Herr, Kardes, \& Kim, 1991). Other researchers have argued that negative information increases attention and is easier to remember (Baumeister, Bratslavsky, Finkenauer, \& Vohs, 2001; Ito, Larsen, Smith, \& Cacioppo, 1998; Pratto \& John, 1991; Taylor, 1991). A study by Liem, Zandstra, and Thomas (2010) found that parents who predicted the ice cream preferences of their 3 to 10-year-old children were more accurate at predicting dislikes than likes, presumably because children communicated dislikes more consistently. Research on the evolutionary origins of food preferences has shown that strong dislikes and feelings of disgust are distinct and quite stable over time (e.g., Olatunji et al. 2012; Rozin, Haidt, \& McCauley, 1993; Rozin et al. 1999), which presumably makes them easier to predict. 


\section{Stereotypical Preferences}

Recent findings by Pollmann and Scheibehenne (2015) indicate that preference prediction accuracy depends critically on the distribution of preferences within the population rather than on valence per se. Across different domains such as food or movie preferences, they found support for the base rate hypothesis, stating that common, stereotypical preferences that are shared by many people are easier to predict than unique, idiosyncratic preferences.

Presumably, knowing that many people like or dislike an item, sometimes referred to as generic knowledge (Finkenauer \& Righetti, 2011) or stereotype consensus (Gill \& Swann, 2004), may provide valid information that can be utilized when making predictions on an individual level (Acitelli, Kenny, \& Weiner, 2001; Kahneman \& Tversky, 1973; Hoffrage, Lindsey, Hertwig, \& Gigerenzer, 2000; West, 1996). To illustrate, predicting that a given child likes icecream and dislikes broccoli is probably a safe bet. Accordingly, in domains in which preferences are widely shared (e.g., popular foods), likes are better predicted than dislikes, whereas the reverse is true in domains in which preferences vary widely (e.g., avant garde films). These results dovetail with findings by Scheibehenne, Mata, and Todd (2011), who also found higher accuracy for stereotypical preferences shared by many people. While these results seem to contradict the valence-based account outlined above, the two explanations are not mutually exclusive because valence could be an important predictor of accuracy in preference predictions beyond the base rates.

Importantly, rigorously testing the base-rate hypothesis conjointly with the valence account requires that possible alternative explanations be ruled out. For example, in the previous analysis by Pollmann and Scheibehenne (2015), the proportion of people who liked or disliked an item (i.e., the base rates) varied across domains (foods, movies, etc.). Hence it could be that 
the observed effects were due to differences between the respective domains or participants and not to the base rates per se. Ruling out these alternative explanations requires a within-subjects design in which both base rates and valences vary within the same prediction domain.

\section{Extreme Preferences}

Besides valence and base rates, past research also indicates that prediction accuracy depends on the extremeness of an observed preference, i.e., how strongly someone likes or dislikes an item. Although extreme likes and dislikes may often be idiosyncratic and hence have low base rates, not all extreme preferences are necessarily rare. An example of this is the strong general dislike for some ethnic foods such as Surströmming, a fermented herring sold in Sweden that has a pungent, rotten smell.

In their study, Scheibehenne, Mata, and Todd (2011) reported higher predictive accuracy for more extreme preferences. Similar to the arguments for the negative valence hypothesis above, a possible explanation for this is that individuals pay more attention to extremely positive and extremely negative opinions (Gershoff et al., 2003) and that extreme likes and dislikes are more reliable and are expressed more intensely than less extreme preferences (Wetzel, Lüdtke, Zettler, \& Böhnke, 2016). Hence, to rigorously test the extremeness hypothesis against the baserate and the valence hypotheses requires data in which all three factors vary independently of one another.

\section{Similarity}

Past research found that predictive accuracy increases in couples who share similar preferences in the respective domain (Lerouge \& Warlop, 2006). A positive correlation between preference similarity and accuracy may occur if partners use their own preferences to predict 
those of others (e.g., Allport, 1924). Such an "egocentric anchoring" strategy (Naylor, Lamberton, \& Norton 2011) may indeed yield accurate predictions (Davis, Hoch, \& Ragsdale, 1986). Similarity is also a good predictor of attraction (Montoya, Horton, \& Kirchner, 2008). Hence, people tend to associate with other people who are similar to them (i.e., homophily). In addition to this social selection, there is also evidence of social causation, showing that couples' food and taste preferences become more similar over time (Bove, Sobal, and Rauschenbach, 2003). Recently, Groyecka et al. (2018) found that the similarity in taste and olfactory preferences in couples increases with relationship duration. A possible convergence over time may have a positive influence on prediction accuracy in longer relationships (Thomas, Fletcher, \& Lange, 1997). However, couples' similarity is presumably higher for items on which most people agree. Therefore, it is again important to distinguish similarity accounts from the baserate hypothesis outlined above. Such a distinction requires empirical data in which the similarity between partners can be disentangled from how stereotypical their preferences are.

\section{Age and Relationship Duration}

While people are eating out with increasing frequency, in many countries including Germany, most meals are still eaten at home (Orfanos et al. 2009). As partners living in the same household often eat together (Kremmer, Anderson, \& Marshall, 1998), longer relationships provide extended opportunities for learning and feedback. In turn, this can be expected to increase partner knowledge and facilitate predictive accuracy. Accordingly, some studies outside the food domain have found that mutual understanding is higher among couples in long-lasting relationships (e.g., Iafrate, Bertoni, Donato, \& Finkenauer, 2012; West, 1996). However, a metaanalysis of 27 studies found no correlation between predictive accuracy and relationship duration (Fletcher \& Kerr, 2010). Likewise, a more recent longitudinal study of newly married couples 
found no increase in predictive accuracy over a period of four years (Finkenauer \& Righetti, 2011). In the food domain, findings by Scheibehenne et al. (2011) even suggest that elderly couples are less accurate in predicting each other's preferences than younger couples. The authors note that the lower accuracy could be due to a cohort effect (Ellis, Holmes, \& Wright, 2010) or could reflect a general decline in cognitive capacities including memory, attention, or perception with age (Healey \& Hasher, 2009; Salthouse, 2011; see also Ramscar et al., 2014). Hence, even though age and relationship duration are usually correlated in the real world, the two factors make qualitatively different predictions. To disentangle these influences, we collected and statistically analyzed data that make it possible to estimate the effect of couples' relationship duration independently from age.

\section{Relationship Satisfaction and Well-Being}

For attitudes and personality traits, higher predictive accuracy and similarity is positively correlated with relationship quality and emotional well-being (Decuyper, De Bolle \& De Fruyt, 2012; Dunn, Huntsinger, Lun, \& Sinclair, 2008; Pollmann \& Finkenauer, 2009; Reis, Lemay, \& Finkenauer, 2017; Sillars \& Scott, 1983). Past research further indicates that people tend to perceive close acquaintances as being similar to themselves (Alves, Koch, \& Unkelbach, 2016; Montoya, Horton, \& Kirchner, 2008; Weller and Watson, 2009), suggesting a positive correlation between perceived similarity and relationship quality (Furler, Gomez, \& Grob, 2014; Letzring \& Noftle, 2010; Luo \& Snider, 2009). Relationship quality also seems to depend on the similarity in empathic accuracy when predicting thoughts and feelings between partners (e.g., Ickes, 1993; Simpson et al., 1995; Stinson \& Ickes, 1992). In other words, similarity in prediction accuracy correlates with relationship satisfaction, irrespective of actual accuracy. 
The causal link between these variables is not always clear, however. Higher relationship quality could lead to better partner knowledge and higher (perceived) similarity, e.g., because couples spend more time together. On the other hand, partner knowledge and (perceived) similarity might positively influence relationship quality because of fewer misunderstandings and the feeling of being understood.

Irrespective of the causal direction, it is not clear if these links generalize to the food domain. Preparing foods that the partner does not like (indicating low preference knowledge) may decrease relationship satisfaction. Scheibehenne et al. (2011) found no correlation between relationship satisfaction and predictive accuracy in the case of everyday food preferences, although their study may have lacked sufficient statistical power to detect smaller correlations. To overcome these limitations and to test the link between relationship quality and predictive accuracy more rigorously, the study at hand relies on a larger and more representative sample.

\section{Research Questions}

The current study addresses the gaps in the literature described above based on the following research questions: 1. Is it easier to predict likes (positivity effect) or dislikes (negativity effect)? 2. Is it easier to predict common, stereotypical preferences that are shared by many people or unique, idiosyncratic preferences? 3. Are extreme preferences easier to predict than moderate preferences? 4. Does predictive accuracy increase between partners who share similar food preferences? 5. Does accuracy increase with age and/or relationship duration? 6. Does predictive accuracy correlate with relationship satisfaction or well-being?

To address these research questions, we conducted a study in which a representative sample of couples rated their own preferences and predicted their partners' preferences for a number of familiar food items. 


\section{Method}

\section{Sample}

Participants were part of the Innovation Sample of the German Socio-Economic Panel Study (SOEP-IS), established in 2012, which offers researchers the opportunity to collect data tailored to their particular research question (see Richter \& Schupp, 2015). The SOEP-IS is a household panel study in which all household members aged 17 and above are interviewed. SOEP-IS respondents are chosen using a multistage random sampling technique with regional clustering. Refresher samples have been added over time to increase sample size and to maintain the representativeness of the data for the population of households in Germany. Our final sample consisted of 1,416 heterosexual and 11 homosexual couples. Respondents' mean age was 54.5 years $(s d=15.8$ years $)$ with a range from 19 to 94 years.

\section{Food items}

To cover a diverse spectrum of food items and preference ratings, we selected 18 foods that were either high in fat or high in sugar (and thus are often considered unhealthy), or low in both, fat and sugar (and thus are often considered healthy, Duffy et al. 2007). Within each of these three categories (i.e. fatty, sweet, and healthy), foods were selected to cover a wide range of most participants' preferences, from being potentially liked to disliked. Within each of the resulting six categories (e.g. fatty \& potentially liked, fatty \& potentially disliked, etc.), we identified three widely known foods that people of different ages, genders, and socioeconomic 
statuses consume in Germany with variable frequency (Max Rubner-Institut, 2017). To account for the fact that some people in the population do not eat meat (e.g., Pfeiler, \& Egloff, 2018), we used only vegetarian foods. To further increase reliability, we aimed for short and concise descriptions. Example items include honey (high in sugar, potentially liked), licorice (high in sugar, potentially disliked), peanuts (high in fat, potentially liked), tofu sausage (high in fat, potentially disliked), sliced apples (comparably low in sugar $(<10 \%)$, potentially liked) and lowfat yogurt (low in fat, potentially disliked). Figure 1 provides an overview of all food items.

\section{Item presentation and answer scale}

For each couple, one food from each of the six categories was randomly selected and the selected foods were presented in random order. Half of the couples, again randomly assigned, first rated their own and then their partner's preferences on all items. The other half of the couples first rated their own preferences and then their partner's preferences. All participants rated how much they liked each food on a fully anchored seven-point hedonic preference scale ranging from "don't like it at all" (1) to "like it very much" (7). Participants used the same scale to predict their partners' preferences. The data were specifically collected to address the research question at hand. While each couple only rated six foods, the final statistical analysis was based on all 18 foods. As there were thousands of couples in the sample, there are still many observations for each food item.

\section{Measure of Prediction Accuracy and Life Satisfaction}

Prediction accuracy was quantified as the absolute difference between a participant's predictions and the stated preferences of their respective partner (i.e., the "target"). Hence, the measure ranges between 0 (perfect accuracy) and 6 (lowest accuracy). Alternative measures 
established in the literature, such as the root of the mean-squared difference or the absolute order of magnitude error (e.g., Brown \& Siegler, 1992), were highly correlated $(r=.96$ and $r=.93$, respectively) and yield similar results.

As part of the SOEP-IS survey, respondents also answered questions about their life satisfaction in general and their satisfaction with family life in particular on a scale from 0 (very unsatisfied) to 10 (very satisfied). As one question was asked at the end and the other at the beginning of the survey, there was a time lag of about 40 minutes between.

\section{Statistical Analyses}

To test which variables systematically influenced the prediction error, we estimated a multilevel linear regression using the lme4 package in R (version 1.1-13, Bates et al., 2015) ${ }^{1}$. The model accounts for possible dependencies in the data due to the repeated measurement design and is similar to the mean-level bias approach (Fletcher \& Kerr, 2010; Stern \& West, 2018). The regression model assumes random intercepts for individuals, couples, and food items. Predictor variables were tested by adding them consecutively as fixed effects, starting from a baseline model that includes just the intercept as a single fixed effect (denoted m0). We conclude that a given variable has a credible influence on prediction accuracy if adding it to the regression equation improves model fit according to the Bayesian information criterion (BIC) that takes model complexity into account. While absolute BIC values are difficult to interpret, BIC differences $(\triangle \mathrm{BIC})$ can be transformed into Bayes factors $(\mathrm{BF})$, which can be interpreted more

${ }^{1}$ The data analysis script is available online at https://osf.io/teycw/. Due to strict provisions of German data protection law, we cannot make the data publicly available. Researchers can apply for data access free of charge through the German Institute for Economic Research (DIW Berlin). 
intuitively. ${ }^{2}$ In particular, the BF quantifies the evidence for one model over another. For example, a BF of 10 indicates that, based on the observed data, one model was ten times more probable. We relied on this Bayesian model comparison approach to avoid the pitfalls of nullhypothesis significance testing (e.g., Baker, 2016).

As we will outline in more detail in the results section below, the association between prediction accuracy and age as well as between prediction accuracy and relationship duration was analyzed first. Next, the targets' preference ratings were included to test whether prediction accuracy depended on valence. To test whether targets with more extreme preferences were predicted better, an extremeness score was included as an additional prediction that was calculated by taking the absolute difference between targets' ratings on the seven-point preference scale and 4, the middle of the scale. Hence, ratings that are closer to either endpoint of the scale received higher scores. Next, a variable that measured stereotypical preferences was included in the model as a predictor. This variable was calculated based on the absolute difference between each rating and the mean rating for that particular food across all participants. Here, a larger absolute difference indicates a larger deviation from the majority preference and hence a more idiosyncratic and less stereotypical preference. In a next step, we tested whether similarity in couples' likes and dislikes affects prediction accuracy by adding the absolute difference between partners' preferences to the regression model as an additional predictor. Thus, higher difference scores indicate less similarity. Finally, we studied possible links between prediction accuracy and participants' average satisfaction with life in general and with family life in particular as a proxy for relationship quality. In the latter analyses, prediction accuracy was

\footnotetext{
${ }^{2}$ Based on the standard assumption of uninformative priors (Raftery, 1995), the transformation suggested by Wagenmakers (2007) is $B F=\exp (\Delta \mathrm{BIC} / 2)$.
} 
treated as a predictor variable for the satisfaction measures. As outlined in the introduction, the causal direction between these variables is not always clear, but treating satisfaction measures as a dependent variable seems a more common approach in the literature (e.g., Diener \& Diener, 2009).

\section{Missing Data}

For 58 couples ( $4 \%$ of the sample), information about relationship duration was not available, and in $0.5 \%$ of individual food ratings (174 out of 34, 248), responses for food items was missing. We excluded these cases from further analysis to ensure a constant number of observations across all models.

\section{Results}

\section{Descriptive analyses}

The mean self-reported relationship duration was 28.8 years ( $s d=17.5$ years) with a range from 1 to 70 years. Figure 1 provides an overview of the preference ratings (i.e., the ratings on how strongly participants disliked or liked a food on a scale from 1 to 7) for the 18 food items. The ratings differed widely, ranging from the most liked sliced apples $(m=5.8$, $s d=1.35)$ to the least liked tofu sausage $(m=1.9, s d=1.44)$. The mean absolute prediction error across all participants and foods was $1.06(\mathrm{sd}=0.66)$. 


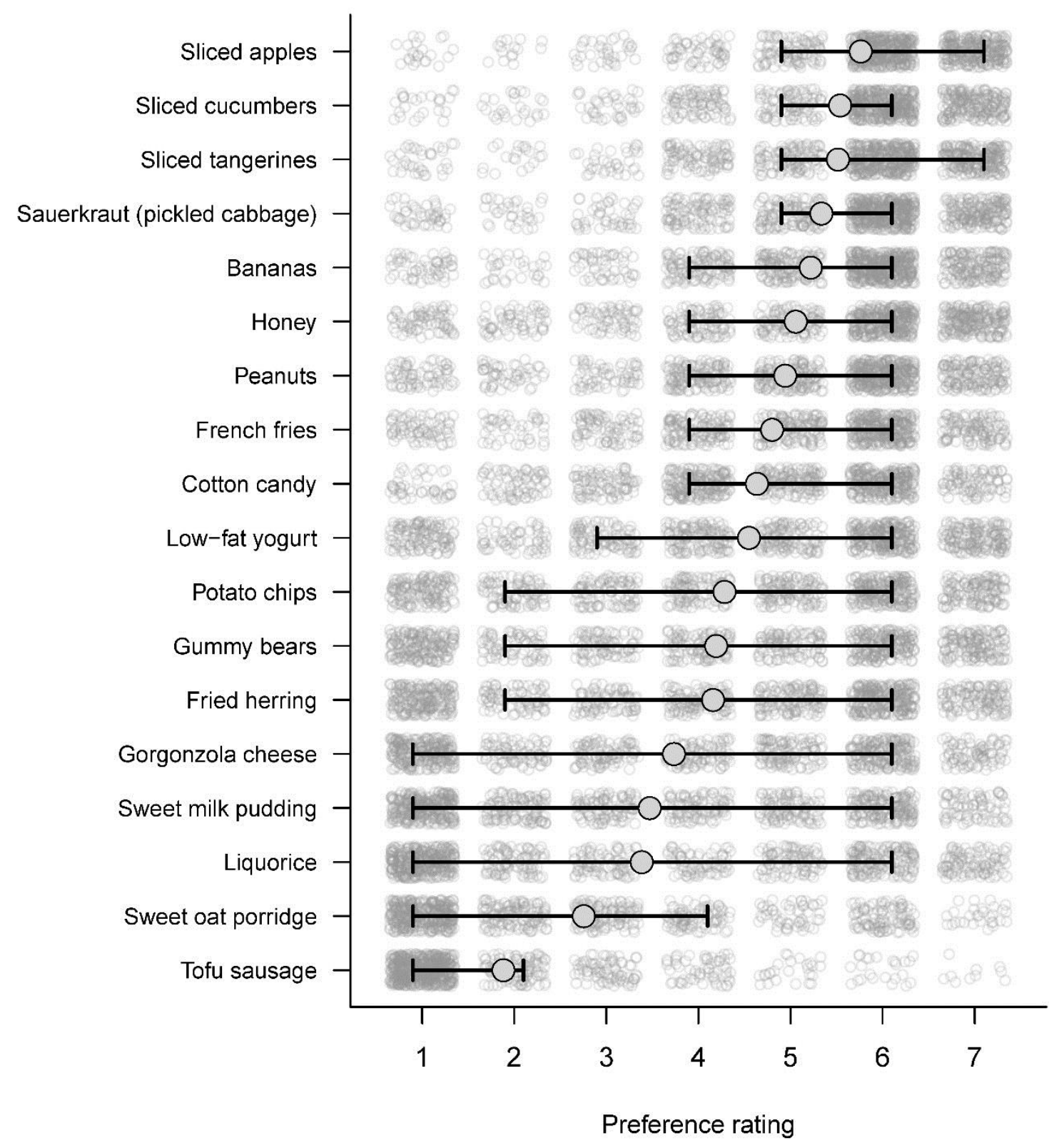

Figure 1: Overview of preference ratings for each of the 18 food items. The large grey shaded dots indicate mean ratings, and error bars indicate the $50 \%$ quantile range. The open grey circles in the background indicate individual ratings with jitter (i.e., a bit of random noise which has been added for better visibility). 


\section{Relationship Duration and Age}

For the intercept-only baseline model (m0), the estimated intercept was 1.06 , indicating that on average, participants' predictions were off by 1 point on the 7-point answer scale. Adding participants' age to the baseline model improved model fit. The difference between the Bayesian information criteria $(\triangle \mathrm{BIC})$ of the baseline model $(\mathrm{m} 0)$ and the extended model $(\mathrm{m} 1)$ was 7 . This difference translates into a Bayes factor $(B F)$ of 33 , indicating that $\mathrm{m} 1$ was 33 times more probable than $\mathrm{m} 0$. This provides strong evidence of a systematic influence of age on food prediction accuracy. The estimated regression coefficient was negative, indicating that prediction error decreased with age and hence that accuracy increased with age. Table 1 gives an overview of the respective parameter estimates. As can be seen from the table, the estimated regression coefficient had a rather small effect. Expressed in absolute terms, an age difference of 10 years would only decrease the absolute prediction error by 0.038 points. Stated differently, a decrease in prediction error by one standard deviation (i.e., 0.66 points) would theoretically require growing 173 years older. 


\begin{tabular}{|c|c|c|c|c|c|c|c|c|}
\hline Linear Model & m0 & m1 & $\mathbf{m} 2$ & $\mathbf{m 3}$ & m4 & m5 & m6 & m7 \\
\hline \multicolumn{9}{|l|}{ Fixed effects } \\
\hline Intercept & 1.064 & 1.273 & 1.213 & 1.132 & 1.672 & 1.918 & 1.661 & 1.375 \\
\hline Age & & -0.004 & & 0.002 & & & & \\
\hline relationship duration & & & -0.005 & -0.007 & -0.006 & -0.006 & -0.005 & -0.004 \\
\hline target preferences & & & & & -0.100 & -0.098 & -0.065 & -0.063 \\
\hline extreme preferences & & & & & & -0.138 & -0.281 & -0.231 \\
\hline idiosyncratic preferences & & & & & & & 0.247 & 0.125 \\
\hline couples' dissimilarity & & & & & & & & 0.205 \\
\hline \multicolumn{9}{|l|}{ Model fit } \\
\hline $\log ($ likelihood $)$ & $-26,379$ & $-26,371$ & $-26,361$ & $-26,360$ & $-26,176$ & $-26,081$ & $-25,888$ & $-25,337$ \\
\hline $\mathrm{BIC}$ & 52,807 & 52,800 & 52,780 & 52,788 & 52,420 & 52,240 & 51,862 & 50,771 \\
\hline
\end{tabular}

Table 1: Overview of the estimated random effects regression models with the absolute prediction error as dependent variable. The upper part of the table contains the estimated fixed effects for the different regression models ( $\mathrm{m} 0$ to $\mathrm{m} 7$ ) that differ based on the number and type of predictors they include. The lower part of the table shows the model fit, quantified as the (log) likelihood of the observed data given the respective model predictions and the Bayesian Information Criterion (BIC), which takes model complexity (i.e., the number of predictor variables) into account. Better model fit is indicated by a higher (log) likelihood and a lower BIC. Here, both measures point to $\mathrm{m} 7$ as the best fitting model. 
As older participants also tend to have lived longer with their partner, that is, spent more time with him or her, the question arises which of the two variables was responsible for the observed effect, age or relationship duration. As a first step toward answering this question, we tested the main effect of relationship duration on prediction accuracy. Including only relationship duration as a fixed effect (m2) increased model fit relative to an intercept-only baseline model $(\triangle \mathrm{BIC}=26.4 ; B F>10,000)$, indicating that longer relationship duration improves prediction accuracy. Including both age and relationship duration as predictors (m3) did not improve the fit above and beyond that of model $\mathrm{m} 2$, which only included relationship duration $(\triangle \mathrm{BIC}=-7.4 ; B F$ $=0.02$ ), indicating that the effect of age was mediated by relationship duration. A mediation analysis on the level of individual participants confirmed this result (Tingley et al. 2014). In absolute terms, the effect of relationship duration was again small, as indicated by the estimated regression coefficients shown in Table 1 . Increasing relationship duration by 30 years would only improve the absolute prediction error by 0.15 points, about a quarter of a standard deviation.

\section{Valence and Extreme Preferences}

Adding the preference rating of the target as an additional predictor (m4) increased model fit relative to model $\mathrm{m} 2(\triangle \mathrm{BIC}=360, \mathrm{BF}>10,000)$. The corresponding regression coefficient was negative, indicating that the prediction error decreased for foods that received higher ratings. In other words, prediction accuracy was higher for likes than for dislikes.

Adding the extremeness score to the regression model (m5) further increased model fit relative to $\mathrm{m} 4(\triangle \mathrm{BIC}=180, \mathrm{BF}>10,000)$. The corresponding regression coefficient was again negative, indicating that the prediction error decreased for foods that received more extreme ratings by partners. Stated differently, predictive accuracy was higher for strong food 
preferences. This was despite the fact that predicting extreme preferences is more difficult a priori because they allow for a larger absolute estimation error.

\section{Stereotypical Preferences}

Including the indicator for stereotypical food preferences as an additional predictor in the regression model (m6) further improves model fit $(\Delta \mathrm{BIC}=377, \mathrm{BF}>10,000)$. The corresponding regression coefficient is positive. Hence, prediction error increases for idiosyncratic preferences, and likewise, prediction accuracy increases for more common, stereotypical preferences. These results show that the valence and base-rate accounts are not contradictory but rather make independent contributions to prediction accuracy. Accordingly, accuracy is highest for strong positive preferences that are shared by many people.

If common preferences increase prediction accuracy, foods for which many people share similar preferences should be predicted more accurately. Such homogenous preferences should then result in lower variance and lower entropy (Shannon, 1948) of the submitted preference ratings for a food item. To test this, we estimated a linear regression model on the level of single foods $(n=18)$ where the dependent variable was the mean absolute prediction accuracy for each food item across all participants and the predictor variable was either the variance or the entropy of participants' preference ratings for each food. Results of these analyses indicate that both variance and entropy are good predictors of prediction accuracy. Compared to an intercept-only model, the evidence for the regression model that includes variance is much higher $(\mathrm{BF}=3,205$; $\Delta \mathrm{BIC}=16.2)$. For entropy, the $\mathrm{BF}$ is $1,003(\Delta \mathrm{BIC}=13.8)$.

Given this effect of variance and entropy, a possible explanation for the increase in prediction accuracy with longer relationship duration could be that older participants (who have been in a relationship for longer) have more homogenous preferences and hence show lower 
variance and entropy. However, further analyses show no credible difference in either variance or entropy between old and young participants or between short and long relationship duration, respectively (indicated by a median split for age and relationship duration). This suggests that the increase in prediction accuracy with relationship duration was not due to differences in preference homogeneity.

\section{Similarity}

Adding dissimilarity between partners to the regression model (m7) as an additional predictor further improved model fit $(\triangle \mathrm{BIC}=1,092, \mathrm{BF}>10,000)$. The corresponding regression coefficient was positive, indicating that similarity increases prediction accuracy. In particular, a one-point increase in similarity increased prediction accuracy by 0.21 points.

To test whether similarity increased with relationship duration and/or depended on age, we estimated another multilevel regression that was similar to the previous one but contained dissimilarity as a dependent variable and relationship duration as a predictor. Results of this analysis indicated that including relationship duration as a predictor explained the data better than an intercept-only model $(\triangle \mathrm{BIC}=7.3, \mathrm{BF}=37)$. The sign of the estimated regression coefficient showed that couples who had been in a relationship for longer were slightly more similar. This is in line with the idea of social causation. The effect was quite small, however. For every ten years of relationship duration, similarity increased by only 0.05 points. Adding participants' age to the regression did not improve model fit further. A mediation analysis on the level of individual participants confirmed that the effect of age on similarity was fully mediated by relationship duration (Tingley et al., 2014). This suggests that the increased similarity in longterm couples was not due to a cohort or generation effect. 
Given that similarity increased slightly with relationship duration, a possible reason for the positive link between relationship duration and prediction accuracy could be that participants in long-term relationships base their predictions to an increasing degree on their own preferences (i.e., use projection). In line with this idea, the difference between respondents' own preferences and their predictions of their partners' preferences decreased slightly with relationship duration, hence indicating more projection as couples live together longer $(\triangle \mathrm{BIC}=12.4, \mathrm{BF}=485)$.

However, this effect could also be driven by greater partner similarity in combination with greater partner knowledge, which is difficult to disentangle with the data at hand.

\section{Satisfaction}

Participants' satisfaction with their life in general and their family life in particular was quite high on average, with observed mean ratings of $7.2(\mathrm{SD}=1.5)$ and $8.5(\mathrm{SD}=1.5)$, respectively, on a scale from 1 to 10 . To test whether making accurate partner predictions affected satisfaction, we estimated a regression with participants' mean absolute prediction error as a predictor and one of the two satisfaction measures as the dependent variable. In a second step, we compared this model to an intercept-only (i.e., "null”) model. Results indicate that individuals who were more accurate in predicting their partners' preferences were also slightly more satisfied with their family life $(\Delta \mathrm{BIC}=5.85, \mathrm{BF}=19)$. With an $\mathrm{R}^{2}$ of 0.0048 , the correlation was very small, however. Accuracy was independent of general life satisfaction, and there was no link between any of the satisfaction measures and how well participants' preferences were predicted by their respective partners or by the absolute difference in couples' prediction error.

Further analyses indicated that couples who shared more similar preferences were slightly more satisfied with family life $(\triangle \mathrm{BIC}=4.56, \mathrm{BF}=9.8)$ and that people who were more satisfied 
with family life relied more on projection $(\triangle \mathrm{BIC}=6.84, \mathrm{BF}=31)$. A possible explanation for the latter result could be that people in happier relationships assume higher similarity between themselves and their partners.

\section{Discussion}

The goal of this study was to identify and empirically test variables that indicate how well couples in relationships know each other's food preferences in a large, nationally representative sample. Results show that prediction accuracy in couples increases with relationship duration rather than with age. Further, accuracy is higher for positive, more common (i.e., stereotypical), and extreme preferences, and in couples who share similar preferences. Accurate partner knowledge goes along with a slightly higher satisfaction with family life but is independent of general life satisfaction.

The results at hand confirm previous findings that likes are predicted more accurately than dislikes, sometimes referred to as a "positivity" effect (e.g., Gershoff, Mukherjee, \& Mukhopadhyay, 2003, 2007; see also Mata et al., 2008). The fact that some previous studies in the food domain reported contrary results, namely that dislikes are more accurately predicted than likes, suggests that the effect of valence on predictive accuracy is sensitive to the specific context and the type of stimuli that are used. In line with this, an important moderating variable seems to be the extremeness of people's food preferences. Our data show that extreme preferences are predicted more accurately. Presumably, couples are more likely to talk about and remember their extreme positive and negative food preferences in order to either seek or avoid these items.

The finding that more stereotypical preferences are predicted more accurately supports the base-rate hypothesis proposed by Pollmann \& Scheibehenne (2015), Scheibehenne et al. 
(2011), and others (e.g., Acitelli et al., 2001; Finkenauer \& Righetti, 2011). Importantly, the results further show that the base-rate and the valence accounts are not mutually exclusive but make independent contributions. This finding extends recent work by Pollmann and Scheibehenne (2015), who tested the two hypotheses against each other. ${ }^{3}$

In line with previous research on social causation in romantic couples (e.g., Thomas, Fletcher, \& Lange, 1997) and dietary convergence in long-term relationships (Bove, Sobal, \& Rauschenbach, 2003; Groyecka et al. 2018), our data suggests that people's food preferences become slightly more similar over the course of their relationships, irrespective of age. Results further show that similarity improves predictive accuracy after controlling for both relationship duration and how stereotypical the preferences are. The latter control variables account for the possibility that a couple's similarity is higher for items on which most people agree. Together, these results provide strong evidence of a positive effect of similarity (see also Lerouge \& Warlop, 2006; Scheibehenne, Mata, \& Todd, 2011). One reason why similarity improves predictions could be that participants project their own preferences (Davis, Hoch, \& Ragsdale, 1986).

Our findings confirm previous findings showing that partner knowledge increases with relationship duration (e.g., Iafrate et al. 2012; West, 1996) but are in contrast to Scheibehenne et al. (2011), who found that elderly couples in long relationships made less accurate predictions than young couples. In extension to the study by Scheibehenne et al., our data allow us to statistically disentangle the influence of age and relationship duration. Thus, one possible explanation for the differing results is that their study relied on a relatively small, cross-sectional

\footnotetext{
${ }^{3}$ For ease of comparison, Figure A1 in the Appendix plots the data in a similar format to Figure 1 in Pollman \& Scheibehenne (2015). As can be seen from the figure, there is a positive slope (indicating the effect of base rates), and most points are above zero on the y-axis (indicating the effect of valence).
} 
convenience sample (20 old and 20 young couples) that was not necessarily representative of the population. The difference could also be due to the type of stimuli, as Scheibehenne et al. (2011) used exotic food dishes rather than common individual food items. Likewise, it could be that couples in new relationships (as was the case in the data used by Scheibehenne et al., 2011) are particularly accurate in their predictions and hence an extreme group (see Thomas, Fletcher, \& Lange, 1997, for a similar pattern in newlywed couples). Given the relatively small effect size in the current data, previous studies that did not find a correlation (see Fletcher \& Kerr, 2010, for an overview) may also have been statistically underpowered or focused on too limited a range in relationship duration.

Finally, our findings show that partner knowledge in the food domain correlates with family life satisfaction. This result extends previous findings showing that the ability to "read" others' thoughts and feelings increases one's own relationship satisfaction (Thomas \& Fletcher, 2003) but differs from the results reported by Pollmann and Finkenauer (2009), who found no correlation between objective partner knowledge of food preferences and relationship satisfaction. The correlation in our data was very small, however, which may explain the difference to Pollmann and Finkenauer who had a smaller sample size and hence lower statistical power.

In our data, having a partner who better predicted one's preferences did not increase satisfaction with family life in the target individuals. This is in line with similar findings by Pollmann and Finkenauer (2009) but stands in contrast to other studies reporting correlations of this kind in the food domain (e.g., Ickes, 1993; Simpson et al., 1995; Stinson \& Ickes, 1992). Likewise, we found no correlation between general life satisfaction and either one's own predictive accuracy or the predictive accuracy of one's partner. A possible reason for these 
missing links could be that concrete knowledge about specific (food) preferences has a negligible influence on general life satisfaction. In line with this, Finkenauer and Righetti (2011) showed that concrete knowledge is often less relevant for satisfaction as compared to people's subjective beliefs about how well their partner knows them or how well they think they know their partner (i.e., "perceived knowledge").

Finally, our data shows that people who are more satisfied with their family life also share more similar preferences with their partners. This correlation aligns with the notion that similarity breeds affection (e.g., Thomas, Fletcher, \& Lange, 1997). Given the cross-sectional data used here, the causal direction could also be reversed.

\section{Limitations and Future Research}

The large, representative sample of participants provides ample statistical power to detect even small effects and allows the results to be generalized to the population level. The selected foods also covered a wide range from strongly disliked to strongly liked, and thus provided the basis to test the research questions at hand. The generalizability of the results is limited, however, by the specific set of 18 food items. Even though the foods were common and included a wide range of ingredients, the selection was somewhat restricted. Also, in many natural settings, people might predict preferences for more complex options such as dishes or meals rather than individual items or ingredients. Besides this, data were collected at one point in time and thus do not provide a basis for assessing the test-retest reliability of the measures in general or the stability of participants' preferences and predictions across time, nor do they allow changes to be tracked over time in couples or individuals. Addressing these questions requires a longitudinal design, and hence remains a task for future research. 
Another limitation of our results concerns the calculation of couples' prediction accuracy as difference scores that depend on similar response biases between partners (Cronbach, 1955; Stern \& West, 2018). For example, both partners might have a tendency to choose higher numbers on the seven-point answer scale, which would erroneously inflate prediction accuracy.

Future research might also consider testing the role of individual differences in taste sensitivity (e.g. due to physiological variation in fungiform papillae (FP) density and 6-npropylthiouracil (PROP) taster status; Duffy \& Bartoshuk, 2000) as potential explanation for some of the variation in the food preferences we observed.

\section{Conclusions}

Eating together or providing food for others is one of the most common daily activities. This study on a large representative sample of partners living together showed the importance of preference characteristics (such as likes versus dislikes) as well as partner characteristics (such as relationship length and shared preferences) for accurate food predictions. While the reported effect sizes were often small, their significance is not: Given that most people living with others make food-related predictions, potentially on a daily basis, even small increases in prediction accuracy could make a notable impact on the population level, for example, reducing resource use for food production and food waste. 


\section{References}

Aschemann-Witzel, J., de Hooge, I., Amani, P., Bech-Larsen, T., \& Oostindjer, M. (2015).

Consumer-related food waste: Ccauses and potential for action. Sustainability, 7, 64576477. doi:10.3390/su7066457

Acitelli, L. K., Kenny, D. A., \& Weiner, D. (2001). The importance of similarity and understanding of partners' marital ideals to relationship satisfaction. Personal Relationships, 8, 167-185. doi:10.1111/j.1475-6811.2001.tb00034.x

Ahluwalia, R. (2002). How prevalent is the negativity effect in consumer environments? Journal of Consumer Research, 29, 270-279. doi:10.1086/341576

Allport, F. H. (1924). Social Psychology. Cambridge, MA: Riverside.

Alves, H., Koch, A., \& Unkelbach, C. (2016). My friends are all alike-the relation between liking and perceived similarity in person perception. Journal of Experimental Social Psychology, 62, 103-117. doi:10.1016/j.jesp.2015.10.011

Bates, D, Maechler, M., Bolker, B, \& Walker, S. (2015). Fitting linear mixed-effects models using lme4. Journal of Statistical Software, 67, 1-48. doi:10.18637/jss.v067.i01

Baker, M. (2016). Statisticians issue warning on $P$ values. Nature, 531, 151. doi:10.1038/nature.2016.19503

Baumeister, R. F., Bratslavsky, E., Finkenauer, C., \& Vohs, K. D. (2001). Bad is stronger than good. Review of General Psychology, 5, 323-370. doi:10.1037/1089-2680.5.4.323

Bove, C. F., Sobal, J., \& Rauschenbach, B. S. (2003). Food choices among newly married couples: Convergence, conflict, individualism, and projects. Appetite, 40, 25-41. doi:10.1016/S0195-6663(02)00147-2 
Brown, N. R., \& Siegler, R. S. (1992). The role of availability in the estimation of national populations. Memory \& Cognition, 20, 406-412. doi:10.3758/BF03210924

Cronbach, L. J. (1955). Processes affecting scores on "understanding of others" and "assumed similarity". Psychological Bulletin, 52, 177-193. doi:10.1037/h0044919

Davis, H. L., Hoch, S. J., \& Ragsdale, E. E. (1986). An anchoring and adjustment model of spousal predictions. Journal of Consumer Research, 13, 25-37. doi:10.1086/209045

Decuyper, M., De Bolle, M., \& De Fruyt, F. (2012). Personality similarity, perceptual accuracy, and relationship satisfaction in dating and married couples. Personal Relationships, 19, 128-145. doi:10.1111/j.1475-6811.2010.01344.x

Diener, E., \& Diener, M. (2009). Cross-cultural correlates of life satisfaction and self-esteem. In E. Diener (Ed.), Culture and Well-Being (Vol. 38, pp. 71-91). Dordrecht: Springer Netherlands. doi:10.1007/978-90-481-2352-0_4

Drewnowski, A., \& Hann, C. (1999). Food preferences and reported frequencies of food consumption as predictors of current diet in young women. The American Journal of Clinical Nutrition, 70, 28-36. doi:10.1093/ajen/70.1.28

Duffy, V. B., \& Bartoshuk, L. M. (2000). Food acceptance and genetic variation in taste. Journal of the American Dietetic Association, 100(6), 647-655. doi: 10.1016/S00028223(00)00191-7

Duffy, V. B., Lanier, S. A., Hutchins, H. L., Pescatello, L. S., Johnson, M. K., \& Bartoshuk, L. M. (2007). Food preference questionnaire as a screening tool for assessing dietary risk of cardiovascular disease within health risk appraisals. Journal of the American Dietetic Association, 107, 237-245. doi:10.1016/j.jada.2006.11.005 
Dunn, E. W., Huntsinger, J., Lun, J., \& Sinclair, S. (2008). The gift of similarity: How good and bad gifts influence relationships. Social Cognition, 26, 469-481. doi:10.1521/soco.2008.26.4.469

Ellis, A. W., Holmes, S. J., \& Wright, R. L. (2010). Age of acquisition and the recognition of brand names: On the importance of being early. Journal of Consumer Psychology, 20, 43-52. doi:10.1016/j.jcps.2009.08.001

Finkenauer, C., \& Righetti, F. (2011). Understanding in close relationships: An interpersonal approach. European Review of Social Psychology, 22, 316-363. doi:10.1080/10463283.2011.633384

Fletcher, G. J. O., \& Kerr, P. S. G. (2010). Through the eyes of love: Reality and illusion in intimate relationships. Psychological Bulletin, 136, 627-658. doi:10.1037/a0019792

Furler, K., Gomez, V., \& Grob, A. (2014). Personality perceptions and relationship satisfaction in couples. Journal of Research in Personality, 50, 33-41. doi:10.1016/j.jrp.2014.02.003

Gershoff, A. D., Mukherjee, A., \& Mukhopadhyay, A. (2003). Consumer acceptance of online agent advice: Extremity and positivity effects. Journal of Consumer Psychology, 13, 161-170. doi:10.1207/S15327663JCP13-1\&2_14

Gershoff, A. D., Mukherjee, A., \& Mukhopadhyay, A. (2007). Few ways to love, but many ways to hate: Attribute ambiguity and the positivity effect in agent evaluation. Journal of Consumer Research, 33, 499-505. doi:10.1086/510223

Gill, M. J., \& Swann, W. B. (2004). On what it means to know someone: A matter of pragmatics. Journal of Personality and Social Psychology, 86, 405-418. doi:10.1037/00223514.86.3.405 
Groyecka, A., Sorokowska, A., Oleszkiewicz, A., Hummel, T., Łysenko, K., \& Sorokowski, P. (2018). Similarities in smell and taste preferences in couples increase with relationship duration. Appetite, 120, 158-162. doi:10.1016/j.appet.2017.08.035

Hartmann, C., Dohle, S., \& Siegrist, M. (2014). Time for change? Food choices in the transition to cohabitation and parenthood. Public Health Nutrition, 17, 2730-2739. doi:10.1017/S1368980013003297

Healey, M. K., \& Hasher, L. (2009). Limitations to the deficit attenuation hypothesis: Aging and decision making. Journal of Consumer Psychology, 19, 17-22. doi:10.1016/j.jcps.2008.12.003

Herr, P. M., Kardes, F. R., \& Kim, J. (1991). Effects of word-of-mouth and product-attribute information on persuasion: An accessibility-diagnosticity perspective. Journal of Consumer Research, 17, 454-462. doi:10.1086/208570

Hoffrage, U.; Lindsey, S.; Hertwig, R.; Gigerenzer, G. (2000). Communicating statistical information. Science, 290, 2261-2262. doi:10.1126/science.290.5500.2261

Iafrate, R., Bertoni, A., Donato, S., \& Finkenauer, C. (2012). Perceived similarity and understanding in dyadic coping among young and mature couples. Personal Relationships, 19, 401-419. doi:10.1111/j.1475-6811.2011.01369.x

Ickes, W. (1993). Empathic accuracy. Journal of Personality, 61, 587-610. doi:10.1111/j.14676494.1993.tb00783.x

Ito, T. A., Larsen, J. T., Smith, N. K., \& Cacioppo, J. T. (1998). Negative information weighs more heavily on the brain: The negativity bias in evaluative categorizations. Journal of Personality and Social Psychology, 75, 887-900. 
Kahneman, D., \& Tversky, A. (1973). On the psychology of prediction. Psychological Review, 80, 237-251. doi:10.1037/h0034747

Kremmer, D., Anderson, A. S., \& Marshall, D. W. (1998). Living together and eating together: Changes in food choice and eating habits during the transition from single to married/cohabiting. The Sociological Review, 46, 48-72. doi:10.1111/1467-954X.00089

Lerouge, D., \& Warlop, L. (2006). Why it is so hard to predict our partner's product preferences: The effect of target familiarity on prediction accuracy. Journal of Consumer Research, 33, 393-402. doi:10.1086/508523

Letzring, T. D., \& Noftle, E. E. (2010). Predicting relationship quality from self-verification of broad personality traits among romantic couples. Journal of Research in Personality, 44, 353-362. doi:10.1016/j.jrp.2010.03.008

Liem, D. G., Zandstra, L., \& Thomas, A. (2010). Prediction of children's flavour preferences. Effect of age and stability in reported preferences. Appetite, 55, 69-75. doi:10.1016/j.appet.2010.04.002

Luo, S., \& Snider, A. G. (2009). Accuracy and biases in newlyweds' perceptions of each other: Not mutually exclusive but mutually beneficial. Psychological Science, 20, 1332-1339. doi:10.1111/j.1467-9280.2009.02449.x

Mata, J., Scheibehenne, B., \& Todd, P. M. (2008). Predicting children's meal preferences: How much do parents know? Appetite, 50, 367-375. doi:10.1016/j.appet.2007.09.001

Max Rubner-Institut, Bundesforschungsinstitut für Ernährung und Lebensmittel (2017).

Häufigkeiten ausgewählter Lebensmittel in der Nationalen Verzehrsstudie II (NVS II). Personal communication on the 30th of November 2017, Karlsruhe, Germany. 
Montoya, R. M., Horton, R. S., \& Kirchner, J. (2008). Is actual similarity necessary for attraction? A meta-analysis of actual and perceived similarity. Journal of Social and Personal Relationships, 25, 889-922. doi: 10.1177/0265407508096700

Naylor, R. W., Lamberton, C. P., \& Norton, D. A. (2011). Seeing ourselves in others: Reviewer ambiguity, egocentric anchoring, and persuasion. Journal of Marketing Research, 48, 617-631. doi:10.1509/jmkr.48.3.617

Olatunji, B. O., Adams, T., Ciesielski, B., David, B., Sarawgi, S., \& Broman-Fulks, J. (2012). The Three Domains of Disgust Scale: Factor structure, psychometric properties, and conceptual limitations. Assessment, 19, 205-225. doi:10.1177/1073191111432881

Orfanos, P., Naska, A., Trichopoulou, A., Grioni, S., Boer, J. M. A., Van Bakel, M. M. E., ... \& Ardanaz, E. (2009). Eating out of home. Energy, macro-and micronutrient intakes in 10 European countries. The European Prospective Investigation into Cancer and Nutrition. European Journal of Clinical Nutrition, 63, 239-262. doi:10.1038/ejcn.2009.84

Parfitt, J., Barthel, M., \& Macnaughton, S. (2010). Food waste within food supply chains: quantification and potential for change to 2050. Philosophical Transactions of the Royal Society of London B: Biological Sciences, 365, 3065-3081. doi:10.1098/rstb.2010.0126

Pollmann, M. M. H., \& Finkenauer, C. (2009). Investigating the role of two types of understanding in relationship well-being: Understanding is more important than knowledge. Personality and Social Psychology Bulletin, 35, 1512-1527. doi:10.1177/0146167209342754

Pollmann, M. M. H., \& Scheibehenne, B. (2015). An information theory account of preference prediction accuracy. Journal of Consumer Psychology, 25, 286-295.

doi:10.1016/j.jcps.2014.10.002 
Pfeiler, T. M., \& Egloff, B. (2018). Examining the "Veggie" personality: Results from a representative German sample. Appetite, 120, 246-255. doi:10.1016/j.appet.2017.09.005

Pratto, F., \& John, O. P. (1991). Automatic vigilance: The attention-grabbing power of negative social information. Journal of Personality and Social Psychology, 61, 380-391. doi:10.1037/0022-3514.61.3.380

Raftery, A. E. (1995). Bayesian model selection in social research. Sociological Methodology, 111-163.

Ramscar, M., Hendrix, P., Shaoul, C., Milin, P., \& Baayen, H. (2014). The myth of cognitive decline: Non-linear dynamics of lifelong learning. Topics in Cognitive Science, 6, 5-42. doi:10.1111/tops.12078

Reis, H. T., Lemay, Jr. E. P., Finkenauer, C. (2017). Toward understanding understanding: The importance of feeling understood in relationships. Social and Personality Psychology Compass, 11.e12308. doi:10.1111/spc3.12308

Richter, D., Schupp, J. (2015): The SOEP Innovation Sample (SOEP IS). Schmollers Jahrbuch 135, 389-399. doi:10.3790/schm.135.3.389

Roos, E., Lehto, R., \& Ray, C. (2012). Parental family food choice motives and children's food intake. Food Quality and Preference, 24, 85-91. doi:10.1016/j.foodqual.2011.09.006

Rozin, P., Haidt, J., \& McCauley, C. R. (1993). Disgust. In M. Lewis \& J. M. Haviland (Eds.), Handbook of emotions (pp. 575-594). New York, NY, US: Guilford Press.

Rozin, P., Haidt, J., McCauley, C., Dunlop, L., \& Ashmore, M. (1999). Individual differences in disgust sensitivity: Comparisons and evaluations of paper-and-pencil versus behavioral measures. Journal of Research in Personality, 33, 330-351. doi:10.1006/jrpe.1999.2251 
Russell, C. G., Worsley, A., \& Liem, D. G. (2015). Parents' food choice motives and their associations with children's food preferences. Public Health Nutrition, 18, 1018-1027. doi:10.1017/S1368980014001128

Salthouse, T. A. (2011). Consequences of age-related cognitive declines. Annual Review of Psychology, 63, 201-226. doi:10.1146/annurev-psych-120710-100328

Scheibehenne, B., Mata, J., \& Todd, P. M. (2011). Older but not wiser-Predicting a partner's preferences gets worse with age. Journal of Consumer Psychology, 21, 184-191. doi:10.1016/j.jcps.2010.08.001

Sillars, A. L., \& Scott, M. D. (1983). Interpersonal perception between intimates: An integrative review. Human Communication Research, 10, 153-176. doi:10.1111/j.14682958.1983.tb00009.x

Shannon, C. E. (1948). A mathematical theory of communication. Bell System Technical Journal, 27, 379-423.

Simpson, J. A., Ickes, W., \& Blackstone, T. (1995). When the head protects the heart: Empathic accuracy in dating relationships. Journal of Personality and Social Psychology, 69, 629641. doi:10.1037/0022-3514.69.4.629

Stern, C., \& West, T. V. (2018). Assessing accuracy in close relationships research: A truth and bias approach. Journal of Social and Personal Relationships, 35, 89-111. doi:10.1177/0265407517712901

Stinson, L., \& Ickes, W. (1992). Empathic accuracy in the interactions of male friends versus male strangers. Journal of Personality and Social Psychology, 62, 787-797. doi:10.1037/0022-3514.62.5.787 
Taylor, S. E. (1991). Asymmetrical effects of positive and negative events: The mobilizationminimization hypothesis. Psychological Bulletin, 110, 67-85. doi:10.1037/00332909.110.1.67

Thomas, G., \& Fletcher, G. J. O. (2003). Mind-reading accuracy in intimate relationships: Assessing the roles of the relationship, the target, and the judge. Journal of Personality and Social Psychology, 85, 1079-1094. doi:10.1037/0022-3514.85.6.1079

Thomas, G., Fletcher, G. J. O., \& Lange, C. (1997). On-line empathic accuracy in marital interaction. Journal of Personality and Social Psychology, 72, 839-850. doi:10.1037/0022-3514.72.4.839

Tingley, D., Yamamoto, T., Hirose, K., Keele, L., \& Imai, K. (2014). Mediation: R package for causal mediation analysis. Journal of Statistical Software, 59, 1-38.

Waldfogel, J. (1993). The Deadweight Loss of Christmas. The American Economic Review, 83, 1328-1336.

Wagenmakers, E. J. (2007). A practical solution to the pervasive problems of p-values. Psychonomic Bulletin \& Review, 14, 779-804. doi:10.3758/BF03194105

Weller, J., \& Watson, D. (2009). Friend or foe? Differential use of the self-based heuristic as a function of relationship satisfaction. Journal of Personality, 77, 731-760. doi:10.1111/j.1467-6494.2009.00563.x

West, P. M. (1996). Predicting preferences: An examination of agent learning. Journal of Consumer Research, 23, 68-80. doi:10.1086/209467

Wetzel, E., Lüdtke, O., Zettler, I., \& Böhnke, J. R. (2016). The stability of extreme response style and acquiescence over 8 years. Assessment, 23, 279-291.

doi:10.1177/1073191115583714 


\section{Appendix}

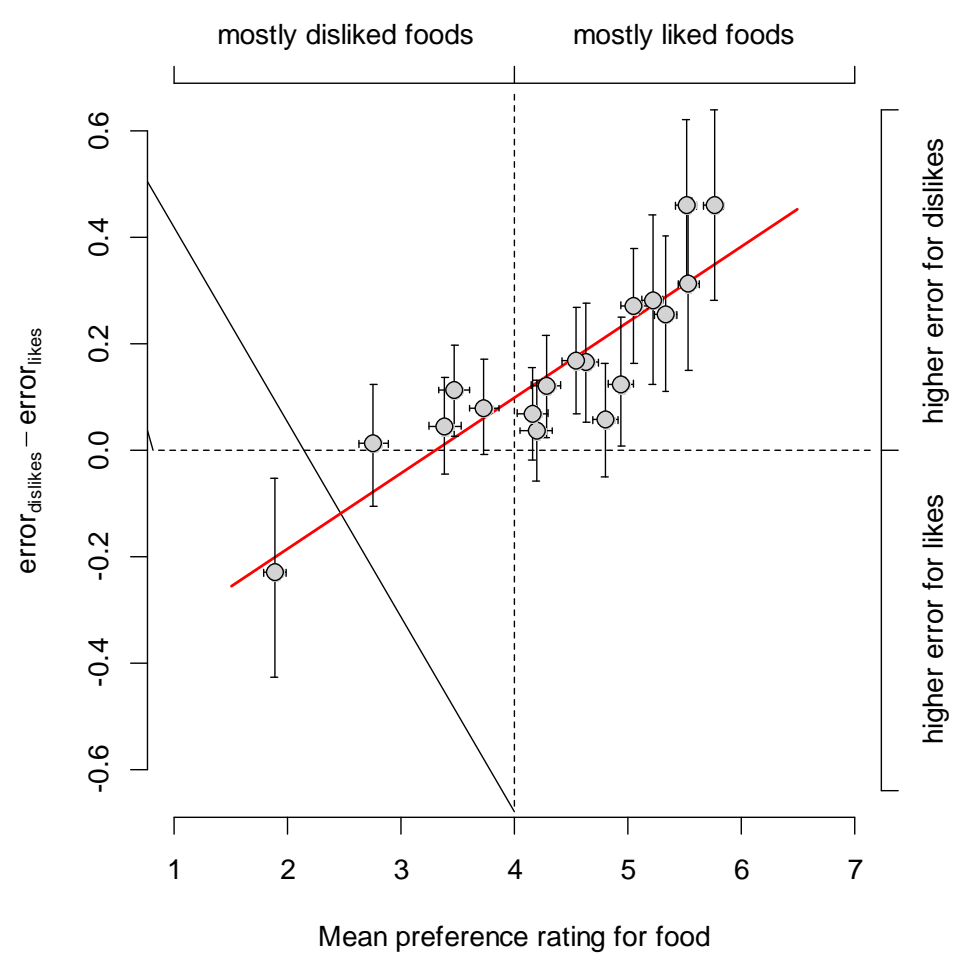

Figure A1: The figure plots the mean preference rating for each of the 18 foods across all participants on the $\mathrm{x}$-axis against the difference between the average prediction accuracy for likes against dislikes on the y-axis. Here, likes are defined as preference ratings $>4$ and dislikes are defined as preference ratings $<4$ on the seven-point answer scale (vertical dotted line). Error bars are bootstrapped $95 \%$ confidence intervals across individual data. Points in the upper half of the figure depict cases where likes were better predicted than dislikes. Points on the right depict cases in which most participants liked the items. As can be seen from the figure, the relative accuracy of predicting likes and dislikes depends on the mean preferences across all participants, indicating a systematic influence of base rates. The red line shows the best-fitting regression. This line is slightly elevated above the diagonal. This indicates that overall, likes are better predicted than dislikes. The figure layout is similar to Figure 1 in Pollmann and Scheibehenne (2015). 